\title{
Do Plano Nacional de Educação (2014-2024) ao Plano Estadual de Educação de Mato Grosso do Sul (2014- 2024): a gestão democrática em questão
}

From the National Education Plan to the State Education (2014-2024) Plan of Mato Grosso do Sul (2014-2024): democratic management issue Del Plan Nacional de Educación (2014-2024) al Plan Estatal de Educación del Mato Grosso do Sul (20142024): la gestión democrática en cuestión

Regina Tereza Cestari de Oliveira*

DOI: http://dx.doi.org/10.20435/serie-estudos.v22i44.1049

\section{Resumo}

Este artigo situa o Plano Nacional de Educação (PNE 2014-2024), aprovado pela Lei n. 13.005, de 14 de junho de 2014, no âmbito de debates, disputas, tensões e contradições que estabelece, entre outros: os estados, o Distrito Federal e os municípios deverão aprovar leis específicas para os seus sistemas de ensino, disciplinando a gestão democrática da educação pública nas suas respectivas esferas de atuação e observando o prazo de dois anos, contado da publicação da mencionada Lei. Assim, focaliza a Meta 19 do PNE 2014-2024 pertinente à gestão democrática, e mostra como o Plano Estadual de Educação de Mato Grosso do Sul (PEE-MS 2014-2024), aprovado pela Lei n. 4.621, de 22 de dezembro de 2014 incorporou a referida meta, associada a critérios técnicos de mérito e desempenho, especialmente, para provimento do cargo de diretores e gestores escolares.

Palavras-chave

Plano Nacional de Educação; Plano Estadual de Educação de Mato Grosso do Sul; gestão democrática da educação.

\section{Abstract}

This article locates the National Education Plan (PNE 2014-2024), approved by Law n. 13.005 of June 14,2014 , in the context of debates, disputes, tensions and contradictions, and establishes, among others: The States, the Federal District and the Municipalities should approve specific laws for their education systems, regulating the democratic management of public education in their respective spheres of expertise and observing the period of two years counting from the date of publication of the establishes Law. Thus, observing the target 19 of PNE 2014-2024 associated to democratic

* Universidade Católica Dom Bosco (UCDB), Campo Grande, Mato Grosso do Sul, Brasil. 
management, which shows how the State Education Plan of Mato Grosso do Sul (PEE-MS 20142024), approved by Law n. 4.621 of december 22, 2014, incorporated this target, related to technical standards of merit and performance, especially, to fill the office of director and school managers.

\section{Key words}

National Education Plan; State Education Plan of Mato Grosso do Sul; democratic management of education.

\section{Resumen}

Este artículo sitúa el Plan Nacional de Educación (PNE 2014-2024), aprobado por la Ley n. 13.005, de 14 de junio de 2014, en el ámbito de debates, disputas, tensiones y contradicciones y establece, entre otros: los estados, el Distrito Federal y los municipios deberán aprobar leyes específicas para sus sistemas de enseñanza, disciplinando la gestión democrática de la educación pública en sus respectivas esferas de actuación y observando el plazo de dos años empezando de la publicación de la mencionada Ley. Asó, focaliza la Meta 19 del PNE 2014-2024 pertinente a la gestión democrática, y muestra como el Plan Estatal de Educación de Mato Grosso do Sul (PEE-MS 2014-2024), aprobado por la Ley n. 4.621, de 22 de diciembre de 2014 incorporo la referida meta, asociada a criterios técnicos de mérito y desempeño, especialmente, para proveimiento del cargo de directores y gestores escolares.

\section{Palabras clave}

Plan Nacional de Educación; Plan Estatal de Educación de Mato Grosso do Sul; gestión democrática de la educación.

\section{INTRODUÇÃO}

Este artigo $^{1}$ situa, no contexto de redefinição do papel do Estado, o Plano Nacional de Educação (PNE 2014-2024), aprovado pela Lei n. 13.005, de 14 de junho de 2014, focaliza a Meta 19, pertinente à gestão democrática, e mostra como o Plano Estadual de Educação de Mato Grosso do Sul (PEE-MS 20142024), aprovado pela Lei n. 4.621, de 22 de dezembro de 2014 incorporou essa meta.

Assim, após 20 anos de ditadura civil-militar, a Constituição Federal de

${ }^{1}$ Este artigo resulta do projeto denominado "Planos de Educação: direito à qualidade e gestão democrática" (Produtividade em pesquisa 2017-2020, CNPq).
1988 incorporou, de certo modo, as reivindicações dos educadores, na medida em que declarou a educação como o primeiro dos direitos sociais ${ }^{2}$ e definiu a gestão democrática entre os princípios ${ }^{3}$

${ }^{2}$ Conforme o Art. 6o Constituição Federal de 1988 são direitos sociais a educação, a saúde, o trabalho, a moradia, o lazer, a segurança, a previdência social, a proteção à maternidade e à infância, a assistência aos desamparados, na forma desta Constituição" (BRASIL, 1988).

3 “O termo princípio é empregado para designar, na norma jurídica escrita, os postulados básicos e fundamentais presentes em todo o Estado de direito, ou seja, são afirmações gerais no campo da legislação a partir a partir das quais devem decorreras demais orientações legais. Geralmente são os princípios que que norteiam o detalhamento dos textos constitucionais" (ADRIÃO; CAMARGO, 2002, p. 72). 
Do Plano Nacional de Educação (2014-2024) ao Plano Estadual de Educação de Mato Grosso do Sul (2014-2024): a gestão democrática em questão

pelos quais se deve pautar a educação brasileira (Art. 205):

I. igualdade de condições para o acesso e permanência na escola;

II. liberdade de aprender, ensinar, pesquisar e divulgar o pensamento, a arte e o saber;

III. pluralismo de ideias e de concepções pedagógicas, e coexistência de instituições públicas e privadas de ensino.

IV. gratuidade do ensino público em estabelecimentos oficiais;

V. valorização dos profissionais da educação escolar, garantidos, na forma da lei, planos de carreira, com ingresso exclusivamente por concurso público de provas e títulos, aos das redes pública;

Vl. gestão democrática do ensino público, na forma da lei;

VII. garantia de padrão de qualidade;

VIII. piso salarial profissional nacional para os profissionais da educação escolar pública, nos termos de lei federal (BRASIL, 1988, grifos nossos).

Como afirma Saviani (2013, p. 216), a aprovação da Constituição finda uma década de grande mobilização e de conquistas no campo educacional. Ressalta que "se os anos de 1980 foram classificados, do ponto de vista econômi- co, como a 'década perdida', no campo da educação estes anos se configuraram como uma década de importantes ganhos".

Desse modo, os direitos sociais declarados e os princípios do ensino incorporados pela Constituição, com a presença inédita da gestão democrática como um desses princípios, apesar de restrita ao ensino publico, indicam avanços em termos de luta dos educadores e de legislação.

As palavras de Peroni (2012, p. 26) são elucidativas ao afirmar que, nesse período,

A gestão democrática é parte do projeto de construção da democratização da sociedade brasileira. Nesse sentido, a construção do projeto político-pedagógico, a participação em conselhos, a eleição para diretores, a autonomia financeira, são processos pedagógicos de aprendizagem da democracia, tanto para a comunidade escolar, quanto para a comunidade em geral, porque a participação, depois de muitos e muitos anos de ditadura, é um longo processo de construção.

A Lei de Diretrizes e Bases da Educação Nacional (LDBEN) reafirmou os princípios do ensino definidos na Constituição Federal de 1988, atribuindo no Inciso VIII do Art. $3^{\circ}$ : "gestão democrática do ensino público, na forma desta Lei e da legislação dos sistemas de ensino" (BRASIL, 1996). Com isso admite 
que, em termos de legislação federal "essa Lei esgota o assunto" (PARO, 2002, p. 80). Isso significa que, ao regulamentar o princípio da gestão democrática definido na Constituição Federal de 1988 (Art. 14), delegou aos sistemas de ensino a prerrogativa de sua construção e operacionalização.

Salienta-se que essa transferência de responsabilidade permitiu que as unidades subnacionais construíssem políticas de gestão de sistemas e de unidades escolares muito diversas, até hoje. Desse modo, encontram-se nos estados e municípios do país aqueles que instituíram instrumentos de democratização da educação (eleição de diretores, eleição de colegiados escolares, instituição de conselhos escolares, construção coletiva do projeto pedagógico da escola), até aqueles em que o provimento do cargo de diretor escolar é exclusivamente ato do poder executivo, assim como as decisões no âmbito escolar são somente emanadas dos sistemas de ensino ou, mesmo quando há projeto pedagógico, este é resultado, apenas, da tarefa exigida pela burocracia institucional (FERNANDES; SCAFF; OLIVEIRA, 2013).

\section{REDEFINIÇÃO DO PAPEL DO ESTADO E GESTÃO EDUCACIONAL}

A partir da promulgação da Constituição Federal de 1988, à medida que no Brasil se criavam mecanismos político-democráticos de regulação da dinâmica capitalista, em âmbito mundial esses mecanismos "perdiam vigência e tendiam a ser substituídos pela ideologia neoliberal, pela desregulamentação, pela flexibilização e pela privatização - elementos inerentes à mundialização (globalização) operada, sob o comando do grande capital" (NETTO, 1999, p. 77, grifos do autor).

É importante lembrar que o neoliberalismo ${ }^{4}$ preconiza a ideia de que o Estado é o principal responsável pela crise econômica que o capitalismo vem atravessando nas últimas décadas, com o argumento de que "[...] gastou mais do que podia para se legitimar, pois tinha que atender às demandas da população por políticas sociais, o que provocou a crise fiscal". E também porque, ao regulamentar a economia, restringe a livre iniciativa", portanto, precisa ser reformado (PERONI; OLIVEIRA; FERNANDES, 2009, p. 764). A base de tal entendimento atingiu os sindicatos es movimentos organizados da sociedade civil. Nas palavras de Anderson (1995, p. 15),

A razão principal dessa transformação foi, sem dúvida, a derrota do movimento sindical, expressão na queda drástica do número de greves durante os anos 80 e numa notável contenção dos salários. Essa nova

${ }^{4}$ O neoliberalismo nasceu logo após a Segunda Guerra Mundial (1939-1945) na Europa e na América do Norte onde imperava o capitalismo e constitui-se numa reação teórica e política contra o Estado intervencionista e de bem-estar. Seu texto de origem é o "O caminho da servidão" de Friedrich Hayek, escrito em 1944 (ANDERSON, 1995, p. 9). 
Do Plano Nacional de Educação (2014-2024) ao Plano Estadual de Educação de Mato Grosso do Sul (2014-2024): a gestão democrática em questão

postura sindical, muito mais moderada, por sua vez, em grande parte era produto de um terceiro êxito do neoliberalismo, ou seja, o crescimento das taxas de desemprego, concebido como um mecanismo natural e necessário de qualquer economia de mercado eficiente.

As ideias neoliberais foram tomando espaço até que, em 1979, foi eleito o governo Thatcher decidido em pôr em prática o programa neoliberal. Na sequência, em 1980, Reagan chegou à presidência dos Estados Unidos. Em 1982, Khol derrotou o regime social liberal de Helmut Schmidt, na Alemanha. Em 1983, com o governo Schluter, a Dinamarca, estado modelo do bem-estar escandinavo, ficou sob o controle de uma coalizão clara de direita. "Em seguida, quase todos os países do norte da Europa ocidental, com exceção da Suécia e da Áustria, também viraram à direita". No entanto, no Chile, quase uma década antes, sob a ditadura de Pinochet, esse regime, "tem a honra de ter sido o verdadeiro pioneiro do ciclo neoliberal da história contemporânea" (ANDERSON, 1995, p. 11-19).

No Brasil, analisa Cury (2013), no momento em que a Constituição da República de 1988 foi promulga$\mathrm{da}$, os intensos ventos provenientes da Inglaterra, dos Estados Unidos, da Austrália e do Chile, sopravam em direção contrária aos direitos sociais claramente proclamados, sendo que conta- vam com o apoio de parte da elite dirigente do país. Assim, prossegue o autor, se, por um lado, a defesa da diminuição do papel do Estado na economia, quanto a esses direitos, acabou por não efetivar muitas das expectativas, por outro, o impacto do conservadorismo liberal não foi mais profundo, pois esses direitos estão declarados na Constituição, assim como no caso da educação, devido ao vínculo entre impostos, percentuais e financiamento.

Na mesma direção, Peroni (2013, p. 19) assinala que a construção da democracia no país viveu um processo de abertura "pactuado com as forças da ditadura", e acentua que, nesse período, já estava em curso, em âmbito mundial, as estratégias para superação da crise do capital, cujas propostas apresentavam-se em sentido contrário ao movimento de luta por direitos sociais, "em um processo de minimização de direitos conquistados".

Nesse contexto, cabe recordar, é que o Plano Diretor da Reforma do Aparelho do Estado (PDRAE), elaborado em 1995, no primeiro mandato do Governo Fernando Henrique Cardoso (1995-1998), pelo então Ministério da Administração e da Reforma do Estado (MARE), na gestão de Luís Carlos Bresser Pereira, identificou o Estado como responsável pela crise econômica, argumentando que "[...] tornou-se claro afinal a causa da desaceleração econômica nos países desenvolvidos e dos graves desequilíbrios na América Latina e no leste europeu, era a crise do Estado 
que não soubera processar de forma adequada a sobrecarga de demandas a ele dirigidas [...]" (BRASIL, 1995, p. 10).

Assim, o governo apresentou a proposta de reformar o Estado, alegando que a crise fiscal impedia a sua capacidade de investimento; deveria fortalecer o seu núcleo estratégico, além de propor a substituição do modelo de administração pública burocrática pela administração pública gerencial, indicada como solução para os problemas de clientelismo, burocratismo e patrimonialismo. O PDRAE afirma que "A reforma do aparelho do Estado passa a ser orientada predominantemente pelos valores da eficiência e qualidade na prestação de serviços públicos e pelo desenvolvimento de uma cultura gerencial nas organizações" (BRASIL, 1995, p. 16).

Nesse conjunto, igualmente crucial para o Estado é o desenvolvimento da forma política do neoliberalismo, geralmente chamada de "Nova Gestão Pública" (new management), destacando-se como uma das suas características-chave "o fato de, em conformidade com o neoliberalismo, não funcionar contra o Estado, mas através dele" (DALE, 2010, p. 1104).

De acordo com Afonso (1998), dessa agenda fazem parte estratégias políticas e econômicas voltadas à revalorização do mercado: reformulação das relações do Estado com o setor privado; adoção de novos modelos de gestão pública centrados na eficácia e na eficiência; assim como redefinição dos direitos sociais.
Com isso, a "Nova Gestão Pública" considera a gestão privada de tipo empresarial, mais racional, eficaz e eficiente, "como regeneradora da administração pública, cujo caráter burocrático seria imanente, e como capaz de vencer as resistências à mudança, que seriam típicas do corporativismo de seus profissionais" (LIMA, 2013, p. 66). Em outras palavras, se o Estado, segundo o diagnóstico do neoliberalismo, por um lado, entrou em crise tanto pela sua ineficiência, como pelo descontrole fiscal, por outro, o mercado e o privado são sinônimos de eficiência, qualidade e equidade (OLIVEIRA; FERNANDES, 2009, p. 59).

Assim, no contexto de redefinição do papel do Estado, a ideia de eficiência presente no PDRAE, como analisam Adrião e Bezerra (2013, p. 264), ganhou status constitucional com o Art. $37 \mathrm{da}$ Emenda Constitucional n. 19 de $1998^{5}$. Em suas palavras,

O status constitucional dado ao princípio da eficiência permitiu a flexibilização das relações entre a iniciativa privada e o poder público, a partir da inserção de práticas gerenciais advindas de modelos privatistas, considerados, nessa perspectiva, mais eficientes e

\footnotetext{
${ }^{5}$ Art. 37 - "A administração pública direta e indireta de qualquer dos Poderes da União, dos Estados, do Distrito Federal e dos Municípios obedecerá aos princípios de legalidade, impessoalidade, moralidade, publicidade e eficiência [...]" (BRASIL, 1988).
} 
Do Plano Nacional de Educação (2014-2024) ao Plano Estadual de Educação de Mato Grosso do Sul (2014-2024): a gestão democrática em questão

ágeis. Além disso, a flexibilização de acordos entre as esferas pública e privada foi ampliada a partir do estabelecimento de parcerias, firmados por um novo instrumento jurídico, dado pela introdução do contrato de gestão no âmbito da Administração Pública.

Segundo essa lógica, iniciativas no âmbito da gestão das políticas educacionais e nos discursos que as justificam, se expressam no entendimento de que é preciso ajustar a gestão dos sistemas de ensino e das escolas ao modelo gerencial. Assim, o foco dos objetivos na gestão democrática é substituído pelas proposições hegemônicas que indicam a seleção de meios que contribuam para o aumento da eficiência e da eficácia da escola (OLIVEIRA; FERNANDES, 2009). Desse modo, nota-se que a ênfase em uma necessária reestruturação institucional das escolas e dos órgãos gestores da educação pública assume a forma do aumento da "responsabilização" da própria escola pela correção das mazelas do sistema educacional público, dos docentes e dos gestores escolares pelos resultados da escola (ADRIÃO, 2006).

Em decorrência, essa responsabilização se manifesta, entre outros, nos resultados da avaliação externa, na premiação pelo sucesso da escola, no estímulo às parcerias entre as escolas e setores privados, como forma "moderna" de participar da melhoria do ensino público. Nesse sentido, modernização implica:
[...] a substituição da lógica do serviço público com o objetivo de garantir direitos de cidadania com vistas à universalização desses direitos, pela lógica do gerenciamento de mercado com o objetivo de otimizar resultados pelas políticas educacionais a partir de sua eficiência e eficácia, buscando assim a qualidade total. (OLIVEIRA; FERNANDES, 2009, p. 68).

Nesse formato de gestão das políticas públicas, materializaram-se, portanto, as mudanças nas políticas educacionais, de um lado, por meio da descentralização das formulações do Poder Executivo central para execução pelos governos subnacionais e, de outro, por meio das parcerias realizadas entre os sistemas públicos de educação com instituições consideradas públicas não estatais (PERONI, 2008).

Diante disso, na análise de Saviani (2007, p. 437), redefine-se tanto o papel do Estado, como o das escolas, prevalecendo o que o autor denomina de "neotecnicismo", ou seja, o controle decisivo desloca-se do processo para os resultados, sendo que pela avaliação dos resultados é que se buscará garantir a eficiência e a produtividade. Nesse sentido, afirma o autor, a avaliação se resume "no principal papel a ser exercido pelo Estado, seja mediatamente, pela criação das agências reguladoras, seja diretamente, como vem ocorrendo na educação". 
A década de 1990, portanto, na análise do mesmo autor, ainda que não seja chamada de "perdida", em contraste com os ganhos dos anos 1980, se caracterizou, no campo da educação, por grandes perdas, "configurando um movimento na contramão daquilo que se apontava com a Constituição promulgada em 5 de outubro de 1988" (SAVIANI, 2013, p. 217).

É nesse contexto que, atendendo a exigência do Art. 87 da Lei de Diretrizes e Bases da Educação Nacional (LDBEN) ${ }^{6}$, o Congresso Nacional aprovou o Plano Nacional de Educação (PNE) para o período 2001 a 2010 pela Lei $n$. 10.172, de 9 de janeiro de 2001, com a vigência de dez anos, sancionada, com vetos ${ }^{7}$, pelo presidente Fernando Henrique Cardoso (1995-2002). Quanto à gestão democrática da educação, nota-se que esse PNE corrobora a LDBEN e define como um dos seus objetivos e prioridades a democratização da gestão do ensino público, nos estabelecimentos oficiais, "obedecendo aos princípios da participação dos profissionais da educação na

${ }^{6} \mathrm{O}$ Art. 14, § 10 da LDBEN estabelece que: "A União, no prazo de um ano a partir da publicação desta Lei, encaminhará, ao Congresso Nacional, o Plano Nacional de Educação, com diretrizes e metas para os dez anos seguintes, em sintonia com a Declaração Mundial sobre Educação para Todos" (BRASIL, 1996).

${ }^{7}$ Ressalte-se que os nove vetos incidiram sobre o aspecto financeiro, o que pode indicar, segundo Saviani (2014, p. 81), que "o objetivo do governo era evitar qualquer possibilidade de ampliação dos recursos da União investidos na educação". elaboração do projeto pedagógico da escola e a participação das comunidades escolar e local em conselhos escolares ou equivalentes". O mesmo se observa em relação à meta 22 do PNE 2001-2010, isto é, "Definir, em cada sistema de ensino, normas de gestão democrática do ensino público, com a participação da comunidade" (BRASIL, 2001, s.p).

Na década seguinte ${ }^{8}$, ao vencer o prazo legal de vigência do PNE 20012010, teve início o processo de discussão, tramitação e aprovação do novo $\mathrm{PNE}$, a ser abordado na próxima seção.

\section{PLANO NACIONAL DE EDUCAÇÃO (PNE 2014-2024) E GESTÃO DEMOCRÁTICA}

O governo Luiz Inácio Lula da Silva (2007-2010) enviou ao Congresso Nacional, em dezembro de 2010, proposta de Plano Nacional de Educação (PNE), após a realização da Conferência Nacional de Educação (CONAE), intitulada "Construindo um Sistema Nacional Articulado de Educação: Plano Nacional de Educação, suas Diretrizes e Estratégias de Ação", no período de 28 de março a 10 de abril de 2010, precedida de Conferências Municipais, Estaduais e do Distrito Federal. Ressalte-se que, na

${ }^{8}$ De acordo com Frigotto (2011, p. 237) como conjuntura, a década de 2001 a 2010, começa em janeiro de 2003, com a posse do presidente Luiz Inácio Lula da Silva, entendendo que "não é o tempo cronológico que define uma conjuntura, mas a natureza dos acontecimentos e dos fatos e as forças sociais que os produzem". 
Do Plano Nacional de Educação (2014-2024) ao Plano Estadual de Educação de Mato Grosso do Sul (2014-2024): a gestão democrática em questão

análise de Saviani (2014), o encaminhamento da organização da Conferência foi acertado ao articular, no tema central, a questão da construção do Sistema Nacional de Educação com o Plano Nacional de Educação, na medida em que há uma íntima relação entre esses dois conceitos.

O Projeto de Lei n. 8.035/2010 tramitou na Câmara dos Deputados e no Senado Federal, sendo que o Plano Nacional de Educação 2014-2014, resultado de amplo processo de discussão, confronto de ideias e tensões que envolveu, em conjunto, a participação da sociedade política e de organismos representativos da sociedade civil, foi aprovado pela Lei n. 13.005, de 25 de junho de 2014, e sancionado, sem vetos, pela presidente Dilma Vana Rousseff, no primeiro mandato do seu governo (2011-2014).

O PNE organizado com 20 metas e 253 estratégias, com vigência por 10 anos (2014-2024), estabelece como diretrizes:

I. erradicação do analfabetismo;

II. universalização do atendimento escolar;

III. superação das desigualdades educacionais, com ênfase na promoção da cidadania e na erradicação de todas as formas de discriminação;

IV. melhoria da qualidade da educação;

V. para o trabalho e para a cidadania, com ênfase nos va- lores morais e éticos em que se fundamenta a sociedade;

VI. promoção do princípio da gestão democrática da educação pública;

VII. promoção humanística, científica, cultural e tecnológica do País;

VIII. estabelecimento de meta de aplicação de recursos públicos em educação como proporção do Produto Interno Bruto $\mathrm{PIB}$, que assegure atendimento às necessidades de expansão, com padrão de qualidade e equidade;

IX. valorização dos (as) profissionais da educação;

X. promoção dos princípios do respeito aos direitos humanos, à diversidade e à sustentabilidade socioambiental (BRASIL, 2014, s.p, grifos nossos).

Para o alcance dessas diretrizes, conforme o Art. 13, o poder público deverá instituir, em lei específica, contados 2 anos da publicação da Lei n. 13.005, o Sistema Nacional de Educação (SNE), "responsável pela articulação entre os sistemas de ensino, em regime de colaboração, para efetivação das diretrizes, metas e estratégias do Plano Nacional de Educação" (BRASIL, 2014, s.p).

Salienta-se que essa discussão esteve presente na segunda edição da CONAE, prevista, inicialmente, para fevereiro de 2014, no primeiro mandato do governo Dilma Vana Rousseff (2011- 
2014), porém realizada no período de 19 a 23 de novembro de 2014, em Brasília, após a aprovação do PNE, com o tema central "O PNE na Articulação do Sistema Nacional de Educação: Participação Popular, Cooperação Federativa e Regime de Colaboração".

Segundo o Art. 8o da Lei 13.005, de 25 de junho de 2014, "Os Estados, o Distrito Federal e os Municípios deverão elaborar seus correspondentes planos de educação, ou adequar os planos já aprovados em lei, em consonância com as diretrizes, metas e estratégias previstas neste PNE, definindo o prazo de 1 ano contado da publicação desta lei" (BRASIL, 2014, s.p). Assim, a União, os estados, o Distrito Federal e os municípios devem organizar-se para alcançar as metas e as estratégias de curto, médio e longo prazo até 2024.

Em relação à gestão democrática, o Art. 9o estabelece que "Os Estados, o Distrito Federal e os Municípios deverão aprovar leis específicas para os seus sistemas de ensino, disciplinando a gestão democrática da educação pública nos respectivos âmbitos de atuação" e estabelece "o prazo de 2 anos contado da publicação desta Lei, adequando, quando for o caso, a legislação local já adotada com essa finalidade" (BRASIL, 2014, s.p).

Para tanto, a Meta 19, seguida de oito estratégias, assim define:

[...] assegurar condições, no prazo de 2 (dois) anos, para a efetivação da gestão democrática da educação, associada a critérios técnicos de mérito e desempenho e à consulta pública à comunidade escolar, no âmbito das escolas públicas, prevendo recursos e apoio técnico da União. (BRASIL, 2014).

Como se verifica, associa-se gestão democrática a critérios de mérito e desempenho, e, depois, refere-se à consulta pública à comunidade escolar, levando-se em conta as estratégias transcritas a seguir:

19.1) priorizar o repasse de transferências voluntárias da União na área da educação para os entes federados que tenham aprovado legislação específica que regulamente a matéria na área de sua abrangência, respeitando-se a legislação nacional, e que considere, conjuntamente, para a nomeação dos diretores e diretoras de escola, critérios técnicos de mérito e desempenho, bem como a participação da comunidade escolar;

19.2) ampliar os programas de apoio e formação aos (às) conselheiros (as) dos conselhos de acompanhamento e controle social do Fundeb, dos conseIhos de alimentação escolar, dos conselhos regionais e de outros e aos (às) representantes educacionais em demais conselhos de acompanhamento de políticas públicas, garantindo a esses colegiados recursos financeiros, espaço 
físico adequado, equipamentos e meios de transporte para visitas à rede escolar, com vistas ao bom desempenho de suas funções;

19.3) incentivar os Estados, o Distrito Federal e os Municípios a constituírem Fóruns Permanentes de Educação, com o intuito de coordenar as conferências municipais, estaduais e distrital bem como efetuar o acompanhamento da execução deste PNE e dos seus planos de educação;

19.4) estimular, em todas as redes de educação básica, a constituição e o fortalecimento de grêmios estudantis e associações de pais, assegurando-se lhes, inclusive, espaços adequados e condições de funcionamento nas escolas e fomentando a sua articulação orgânica com os conselhos escolares, por meio das respectivas representações;

19.5) estimular a constituição e o fortalecimento de conselhos escolares e conselhos municipais de educação, como instrumentos de participação e fiscalização na gestão escolar e educacional, inclusive por meio de programas de formação de conselheiros, assegurando-se condições de funcionamento autônomo;

19.6) estimular a participação e a consulta de profissionais da educação, alunos (as) e seus familiares na formulação dos projetos político-pedagógicos, currículos escolares, planos de gestão escolar e regimentos escolares, assegurando a participação dos pais na avaliação de docentes e gestores escolares;

19.7) favorecer processos de autonomia pedagógica, administrativa e de gestão financeira nos estabelecimentos de ensino;

19.8) desenvolver programas de formação de diretores e gestores escolares, bem como aplicar prova nacional específica, a fim de subsidiar a definição de critérios objetivos para o provimento dos cargos, cujos resultados possam ser utilizados por adesão. (BRASIL, 2014).

Essas estratégias indicam, em sua maioria, o "incentivo" e o "estímulo" à construção de instrumentos de gestão democrática (fortalecimento de grêmios estudantis e associações de pais; fortalecimento de conselhos escolares e conseIhos municipais de educação; ampliação de programas de apoio e formação aos (às) conselheiros (as) dos conselhos de acompanhamento e controle social, por exemplo, do Fundo de Manutenção e Desenvolvimento da Educação Básica e de Valorização dos Profissionais da Educação (Fundeb); participação e consulta de profissionais da educação, alunos (as) e seus familiares na formulação dos projetos político-pedagógicos, 
currículos escolares, planos de gestão escolar e regimentos escolares.

Chama-se a atenção para a Estratégia 19.8 que especifica a aplicação de "prova nacional específica", como um dos critérios para provimento do cargo de diretores e gestores escolares. Essa estratégia indica a avaliação centrada no desempenho, com base no princípio de eficiência, no sentido de atingir o máximo de resultados com o mínimo de dispêndio, e combina com uma das características da nova proposta de gestão pública. E mais, verifica-se que a Estratégia 19.1 prioriza o repasse de transferências voluntárias da União na área da educação para os entes federados que levarem em consideração os critérios técnicos de mérito e desempenho.

Como aqui mencionado, a partir da década de 1990, sob a égide da lógica neoliberal, o princípio de eficiência vem se afirmando na administração pública e, também, na educação brasileira. Pode-se afirmar, utilizando as palavras de Frigotto (2011, p. 245) que, "[...] dentro dessa lógica, é dada ênfase aos processos de avaliação de resultados, balizados pelo produtivismo e à sua filosofia mercantil, em nome da qual os processos pedagógicos são desenvolvidos mediante a pedagogia das competências"'.

9 De acordo com Saviani (2007, p. 435), “'a pedagogia das competências' apresenta-se como outra face da 'pedagogia do aprender a aprender', cujo objetivo é dotar os indivíduos de comportamentos flexíveis que lhes permitam ajustar-se às condições de uma sociedade em que as próprias necessidades de sobrevivência
No entanto é preciso assinalar, utilizando as palavras de Cury (2013, p. 205), "isto não retira a criatividade dos entes federativos em enriquecer e ampliar", pois não se pode esquecer que compete aos estados e aos municípios brasileiros, no exercício de sua autonomia, de seu planejamento das políticas educacionais e das relações sociais vigentes, estabelecer critérios para a gestão democrática da educação em seus planos de educação.

\section{PLANO ESTADUAL DE EDUCAÇÃO (PEE-MS 2014-2024) E GESTÃO DEMOCRÁTICA}

No caso de Mato Grosso do Sul, - Plano Estadual de Educação (PEEMS 2014-2024) foi aprovado pela Lei n. 4.621 de 22 de dezembro de 2014 (MATO GROSSO DO SUL, 2014), após a realização de seminários regionais e da discussão e aprovação do Texto Base no "Seminário Estadual de Educação: construindo coletivamente o Plano Estadual de Educação" (PEE-MAS 2014-2024) (MATO GROSSO DO SUL, 2014, p. 5).

A "Análise Situacional" apresentada no documento, fundamentando a Meta 19-Gestão democrática, menciona que a primeira regulamentação referente à gestão democrática do ensino no estado se deu por meio do Decreto

não estão garantidas. Sua satisfação deixou de ser um compromisso coletivo, ficando sob a responsabilidade dos próprios sujeitos que, segundo a raiz etimológica dessa palavra, se encontram subjugados à 'mão invisível do mercado'". 
Do Plano Nacional de Educação (2014-2024) ao Plano Estadual de Educação de Mato Grosso do Sul (2014-2024): a gestão democrática em questão

n. 5.868, de 1991, que instituiu eleição como mecanismo para preenchimento do cargo de diretor e de diretor adjunto das unidades escolares, garantindo a participação de pais, professores, funcionários e alunos. Instituiu, também, mediante eleição, o colegiado escolar, sendo o diretor membro nato e secretário executivo do órgão (MATO GROSSO DO SUL, 2014, p. 101).

Além disso, refere-se à Lei n. 2.787, de 24 de dezembro de 2003, que dispõe sobre o Sistema Estadual de Ensino e elenca, em seu Art. 3o, os princípios da educação escolar no estado de Mato Grosso do Sul, dentre os quais (VI) "gestão democrática do ensino" (MATO GROSSO DO SUL, 2014, p. 102).

Ressalte-se que o Art. 36 dessa Lei afirma que "A Gestão Democrática do Ensino, entendida como princípio e prática político-filosófica e como ação coletiva, norteará todas as ações de planejamento, formulação, implementação e avaliação das políticas educacionais e alcançará todas as entidades e organismos integrantes do Sistema Estadual de Ensino", sendo que os princípios da gestão democrática, conforme o Art. 37, são: "I. transparência nos mecanismos pedagógicos, administrativos e financeiros; II. respeito à organização dos segmentos da comunidade escolar; III. autonomia político-pedagógica e administrativa". Além disso, o Art. 38 define que sua efetivação se dará mediante a participação da comunidade escolar na: elaboração do Plano Estadual de Educação com efetiva participação da sociedade sul-mato-grossense; elaboração e aprovação da proposta pedagógica e do regimento escolar pelas instituições de ensino; avaliação da aprendizagem dos educandos, do desempenho dos profissionais da educação e da instituição; e "indicação de diretores, nas escolas públicas, com participação efetiva da comunidade escolar, adotado o sistema eletivo, mediante voto direto proporcional e secreto na forma da lei ou regulamento próprio" (MATO GROSSO DO SUL, 2004, p. 16-17).

Outra legislação citada na "Análise Situacional" é a Lei n. 3.244, de 6 de junho de 2006, aprovada no segundo mandato do governo José Orcírio Miranda dos Santos (2003-2006), do Partido dos Trabalhadores (PT). Essa Lei regulamentou para a Rede Estadual de Ensino a eleição para diretor e diretor-adjunto pela comunidade escolar, por meio do voto direto, secreto e proporcional, assim como a escolha do colegiado escolar, constituído por representantes de todos os segmentos que compõem a comunidade escolar (MATO GROSSO DO SUL, 2006).

No entanto a Lei n. 3.479, de 20 de dezembro de 2007, aprovada no primeiro mandato do governo André Puccinelli (2007-2010), do Partido do Movimento Democrático Brasileiro (PMDB), alterou as normas para a eleição de diretores escolares da Rede Estadual de Ensino do Estado de Mato Grosso do Sul. Portanto o processo deixou de ser por eleição direta e passou a ser seletivo, conforme o Art. 1으, em três etapas: I. curso de capa- 
citação em Gestão Escolar; II. avaliação de competências básicas de dirigente escolar; III. eleição (MATO GROSSO DO SUL, 2007).

A Secretaria de Estado de Educação de Mato Grosso do Sul, responsável pela organização do processo seletivo, estabeleceu parceria com a Fundação Luís Eduardo Magalhães (FLEM), uma instituição privada pertencente ao Terceiro Setor, com o objetivo de oferecer curso de capacitação, avaliar as competências básicas por meio da aplicação de prova escrita e, em decorrência, oferecer certificação ocupacional aos candidatos aprovados, que poderiam, na sequência, concorrer à eleição (BIGARELLA, 2015).

Nota-se, ainda, na "Análise Situacional" a referência ao Decreto $n$. 13.770, de 19 de setembro de 2013, documento mais recente, que revogou o Decreto n. $12.500 / 2008$, e passou a vigorar com a seguinte redação:

Art. 15. O processo de seleção de dirigentes escolares para a Rede Estadual de Ensino observará as seguintes etapas:

I. seleção interna no âmbito da unidade escolar, caso o número de interessados seja superior ao número de vagas oferecidas;

II. participação no Curso de Gestão Escolar;

III. participação da avaliação das competências básicas para dirigentes escolares;

IV. elaboração e apresentação à comunidade escolar e à Secretaria de Estado de Educação de projeto de Gestão Escolar;

V. eleição;

VI. designação para o exercício da função pelo titular da Secretaria de Estado de Educação.

Parágrafo único. Os candidatos considerados aptos nas etapas de I a IV descritas no caput integrarão um Banco Único de Dados e poderão participar da eleição conforme o disposto no $\S 2$ 잉 do art. 1 ㅇ da Lei n. 3.479, de 20 de dezembro de 2007 (MATO GROSSO DO SUL, 2014, p.102).

Com base na legislação citada, conclui-se, na "Análise Situacional", que "a rede estadual de ensino de Mato Grosso do Sul possui dispositivos para a efetivação da gestão democrática da educação, sendo necessário garantir sua continuidade e aperfeiçoar seu funcionamento" (MATO GROSSO DO SUL, 2014, p 102).

Observa-se que, em consonância com esse entendimento, o PEE-MS 20142024 define a Meta 19 em concordância com o PNE 2014-20124 e estabelece 15 estratégias, destacando-se, entre elas, a Estratégia 19.1, ou seja: "aprovar lei específica para o sistema de ensino e disciplinar a gestão democrática da educação pública, no prazo de dois anos contados da data de publicação do PNE, adequando à legislação local já adotada com essa finalidade" (MATO GROSSO DO SUL, 2014, p. 103). 
Do Plano Nacional de Educação (2014-2024) ao Plano Estadual de Educação de Mato Grosso do Sul (2014-2024): a gestão democrática em questão

Em relação ao provimento do cargo de diretores e gestores escolares, verifica-se na estratégia 19.12: "participar de programas nacionais de formação de diretores e gestores escolares, bem como da prova nacional específica, a fim de subsidiar a definição de critérios objetivos para o provimento das funções" (MATO GROSSO DO SUL, 2014, p. 103).

Com isso, no âmbito de debates, disputas e contradições, decide-se no PEE-MS 2014-2024 aplicar "prova nacional específica" para seleção de diretores e gestores escolares, adequando a legislação em vigor na Rede Estadual de Ensino de Mato Grosso do Sul, uma vez que a seleção dos candidatos para provimento do cargo de "dirigentes escolares", já sucedia com base no mérito para garantir a eficiência e a eficácia.

É importante mencionar que, quanto ao processo de escolha para provimento do cargo de diretores escolares no país, grosso modo, verificam-se três modalidades: nomeação direta pelo poder executivo, concurso público e eleição pela comunidade escolar (PARO, 2011). Porém verifica-se a modalidade que combina a aplicação de avaliação de competências básicas, mediante prova escrita aos candidatos, seguida de eleição, como é o caso do processo seletivo na Rede Estadual de Ensino de Mato Grosso do Sul, aqui mencionado. Apesar de não constituir nenhuma certeza em termos da democratização da escola, na medida em que é apenas uma das medidas necessárias, entende-se que "a eleição é a única que tem virtude para contribuir para o avanço de tal democratização (PARO, 2011, p. 47), associada às dimensões participação colegiada nas decisões e autonomia das escolas, pois elas podem dar sentido a espaços e tempos organizacionais, individuais e coletivos, de diálogo e deliberação (AFONSO, 2010).

\section{CONSIDERAÇÕES FINAIS}

Buscou-se neste artigo trazer algumas reflexões para o debate acerca da Meta 19 do Plano Nacional de Educação (PNE 2014-2014), referente à gestão democrática, e sobre essa mesma Meta no Plano Estadual de Educação de Mato Grosso do Sul (PEE-MS 2014-2014).

Diante do exposto, considera-se que, embora a gestão democrática esteja definida na Constituição Federal de 1988 como um dos princípios do ensino, e, portanto, voltada para um processo de decisão baseado na participação e na deliberação púbica (CURY, 2007), contraditoriamente, a Meta 19 do PNE 2014-2024 associa essa gestão a critérios técnicos de mérito e de desempenho e define uma "prova nacional específica", seguida de consulta pública à comunidade escolar (BRASIL, 2014) para provimento do cargo de diretores e gestores escolares, meta esta incorporada, por sua vez, no PEE-MS 2014-2024.

Feitas essas considerações, é possível afirmar que a gestão democrática, apesar de mecanismos historicamente construídos na educação brasileira, 
ainda tem um extenso caminho a ser percorrido, no âmbito de um projeto de escola pública de qualidade que se quer no país, articulado com a constru- ção do Sistema Nacional de Educação (SAVIANI, 2014), tendo em vista o crescimento da sociedade enquanto sociedade democrática.

\section{REFERÊNCIAS}

ADRIÃO, T. Educação e produtividade: a reforma do ensino paulista e a desobrigação do Estado. São Paulo: Xamã, 2006.

ADRIÃO, T.; BEZERRA, E. O setor não lucrativo na gestão da educação pública: corresponsabilidade ou debilidade. Currículo sem Fronteiras, v. 13, n. 2, p. 256-268, maio/ago. 2013.

ADRIÃO, T.; CAMARGO, R. B. A gestão democrática na Constituição de 1988. OLIVEIRA, R. P.; ADRIÃO, T. (Org.). Gestão, financiamento e direito à educação: análise da LDB e da Constituição Federal. São Paulo: Xamã, 2002. p. 69-78.

AFONSO, A. J. Gestão, autonomia e accountability na escola pública portuguesa: breve diacronia. Revista Brasileira de Política e Administração da Educação, v. 26, n. 1, p. 13-30, jan./abr. 2010.

. Políticas educativas e avaliação educacional: para uma análise sociológica da reforma educativa em Portugal (1985-1995). Braga, Portugal: Universidade do Minho, 1998.

ANDERSON, P. Pós-neoliberalismo: as políticas sociais e o Estado democrático. São Paulo: Paz e Terra, 1995.

BIGARELLA, N. O papel do Conselho Estadual de Educação de Mato Grosso do Sul na definição de políticas de gestão para a educação básica no período 1999 a 2014. 2015. Tese (Doutorado em Educação) - Universidade Católica Dom Bosco, Campo Grande, MS, 2015.

BRASIL. Lei n. 13.005, de 25 de junho de 2014. Aprova o Plano Nacional de Educação e dá outras providências. Brasília, 2014. Disponível em: <http://www.planalto.gov.br/ccivil>. Acesso em: 10 maio 2015.

. Lei 10.172, de 9 de janeiro de 2001. Aprova o Plano Nacional de Educação e dá outras providências. Brasília, 2001. Disponível em: <http://portal.mec.gov.br/arquivos/pdf/ L10172.pdf>. Acesso em: 10 maio 2015.

. Lei n. 9.394, de 20 de dezembro de 1996. Estabelece as Diretrizes e Bases da Educação Nacional. Brasília, 1996. Disponível em: <http://www.planalto.gov.br/ccivil>. Acesso em: 10 maio 2015.

. Plano Diretor da Reforma do Aparelho do Estado. Brasília: MARE, 1995.

. Constituição da República Federativa do Brasil. Diário Oficial da União. Brasília 5 out. 1988. Disponível em: <www.planalto.gov.br/ccivil>. Acesso em: 10 maio 2015. 
Do Plano Nacional de Educação (2014-2024) ao Plano Estadual de Educação de Mato Grosso do Sul (2014-2024): a gestão democrática em questão

CURY, C. R. J. Sentidos da educação na Constituição Federal de 1988. Revista Brasileira de Política e Administração da Educação, v. 29, n. 2, p. 195-206, maio/ago. 2013.

. A gestão democrática na escola e o direito à educação. Revista Brasileira de Política e Administração da Educação, v. 23, n. 3, p. 483-495, set./dez. 2007.

DALE, R. A sociologia da educação e o Estado após a globalização. Educação e Sociedade, Campinas, SP, v. 31, n. 113, p. 1099-1120, out./dez. 2010.

FERNANDES, M. D.; SCAFF, E. A. S.; OLIVEIRA, R. T. C. Direito à educação e compromisso docente: quando o sucesso e o fracasso escolar encontram o culpado. Revista Brasileira de Política e Administração da Educação, v. 29, n. 2, p. 327-345, maio/ago. 2013.

FRIGOTTO, G. Os circuitos da história e o balanço da educação no Brasil na primeira década do século XXI. Revista Brasileira de Educação, Rio de Janeiro, v. 16, n. 46, p. 235-254, jan./ abr. 2011.

LIMA, L. C. Diretor (a) de escola pública: unipessoalidade e concentração do poder no quadro de uma relação subordinada. In: PERONI, V. M. V. (Org.). Redefinições das fronteiras entre o público e o privado: implicações para a democratização da educação. Brasília: Líber Livro, 2013. p. 58-81.

MATO GROSSO DO SUL. Lein. 4.621, de 22 de dezembro de 2014. Aprova o Plano Estadual de Educação de Mato Grosso do Sul, e dá outras providências. Campo Grande, MS: Secretaria de Estado de Educação, 2014.

. Decreto n. 13.770, de 19 de setembro de 2013. Dispõe sobre a estrutura de funcionamento das unidades escolares da Rede Estadual de Ensino e dá outras providências. Diário Oficial Estado de Mato Grosso do Sul n. 8.520, de 20 de setembro de 2013. Campo Grande, 2013.

. Lei n. 3.479, de 20 de dezembro de 2007. Dispõe sobre o processo eletivo de dirigentes escolares da rede estadual de ensino, dá nova redação aos dispositivos da Lei n. 3.244, de 6 de junho de 2006, e dá outras providências. Diário Oficial [Estado de Mato Grosso do Sul], Campo Grande, MS, n. 7.118, de 21 dez. 2007.

. Lei n. 2.787, de 24 de dezembro de 2003. Dispõe sobre o Sistema Estadual de Ensino de Mato Grosso do Sul e dá outras providências. Campo Grande, MS: Secretaria de Estado de Educação, 2004.

NETTO, J. P. FHC e a política social. In: LESBAUPIN, I. (Org.). O desmonte da nação: balanço do governo FHC. Petrópolis, RJ: Vozes, 1999.

OLIVEIRA, R. T. C.; FERNANDES, M. D. E. Redefinição do papel do Estado no Brasil: implicações do modelo gerencial para as políticas de gestão da educação básica. Educação: Teoria e Prática, Rio Claro, SP, v. 19, n. 32, p. 57-72, jan./jun. 2009.

PARO, V. H. Crítica da estrutura da escola. São Paulo: Cortez, 2011. 
O princípio da gestão escolar democrática no contexto da LDB. In: OLIVEIRA, R. P.; ADRIÃO, T. (Org.). Gestão, financiamento e direito à educação: análise da LDB e da Constituição Federal. São Paulo: Xamã, 2002. p. 79-88.

PERONI, V. A privatização do público: implicações para a democratização da educação. In: PERONI, V. (Org.). Redefinições das fronteiras entre o público e o privado: implicações para a democratização da educação. Brasília: Líber Livro, 2013. p. 9-32.

A gestão democrática da educação em tempos de parceria entre o público e o privado. Pro-Posições, Campinas, SP, v. 23, n. 2 (68), p. 19-31, maio/ago. 2012.

A relação público/privado e a gestão da educação em tempos de redefinição do papel do Estado. In: ADRIÃO, T.; PERONI, V. Público e privado na educação: novos elementos para o debate. São Paulo: Xamã, 2008. p. 111-127.

PERONI, V. M. V.; OLIVEIRA, R. T. C.; FERNANDES, M. D. E. Estado e terceiro setor: as novas regulações entre o público e o privado na gestão da educação básica brasileira. Educação e Sociedade, Campinas, SP, v. 30, n. 108, p. 761-778, out. 2009.

SAVIANI, D. Sistema Nacional de Educação e Plano Nacional de Educação: significado, controvérsias e perspectivas. Campinas, SP: Autores Associados, 2014.

. A educação na Constituição Federal de 1988: avanços no texto e sua neutraliza-

ção no contexto dos 25 anos de vigência. Revista Brasileira de Política e Administração da Educação, v. 29, n. 2, p. 207-221, maio/ago. 2013. . História das idéias pedagógicas. Campinas, SP: Autores Associados, 2007.

\section{Sobre a autora:}

Regina Tereza Cestari de Oliveira: Professora no Programa de Pós-Graduação em Educação Mestrado e Doutorado, da Universidade Católica Dom Bosco (UCDB). Doutora em Educação pela Universidade Estadual de Campinas (UNICAMP). Pós-Doutora em Ciências da Educação, pela Universidade do Minho, Portugal. Pesquisadora produtividade 2, CNPq. E-mail: reginacestari@hotmail.com

\section{Recebido em janeiro de 2017.}

\section{Aprovado para publicação em março de 2017.}

